\title{
Hispanic Ethnicity and Post-traumatic Stress Disorder after a Disaster: Evidence from a General Population Survey after September 11, 2001
}

\author{
SANDRO GALEA, MD, DRPH, DAVID VLAHOV, PHD, MELISSA TRACY, \\ DONALD R. HOOVER, PHD, HEIDI RESNICK, PHD, AND DEAN KILPATRICK, PHD
}

\begin{abstract}
PURPOSE: To assess ethnic differences in the risk of post-traumatic stress disorder (PTSD) after a disaster, and to assess the factors that may explain these differences.

METHODS: We used data from a representative survey of the New York City metropolitan area $(n=2616)$ conducted 6 months after September 11, 2001. Linear models were fit to assess differences in the prevalence of PTSD between different groups of Hispanics and non-Hispanics and to evaluate potential explanatory variables.

RESULTS: Hispanics of Dominican or Puerto Rican origin (14.3\% and $13.2 \%$, respectively) were more likely than other Hispanics $(6.1 \%)$ and non-Hispanics $(5.2 \%)$ to report symptoms consistent with probable PTSD after the September 11 terrorist attacks. Dominicans and Puerto Ricans were more likely than persons of other races/ethnicities to have lower incomes, be younger, have lower social support, have had greater exposure to the September 11 attacks, and to have experienced a peri-event panic attack upon hearing of the September 11 attacks; these variables accounted for $60 \%$ to $74 \%$ of the observed higher prevalence of probable PTSD in these groups.

CONCLUSION: Socio-economic position, event exposures, social support, and peri-event emotional reactions may help explain differences in PTSD risk after disaster between Hispanic subgroups and non-Hispanics.

Ann Epidemiol 2004;14:520-531. (C) 2004 Elsevier Inc. All rights reserved.
\end{abstract}

KEY wORDS: Post-traumatic Stress Disorder, Race, Ethnicity, Hispanic, Disaster.

\section{INTRODUCTION}

The role of race/ethnicity in the development of post-traumatic stress symptoms and post-traumatic stress disorder (PTSD) in the aftermath of traumatic events remains unclear. A few studies have documented racial/ethnic differences in the incidence of post-traumatic symptoms after police work and combat exposure $(1,2)$. The National Vietnam Veterans' Readjustment Survey (NVVRS) documented higher incidence of PTSD among Hispanics than among Whites or Blacks (3-5). There is a paucity of studies that have assessed differences in PTSD prevalence between different Hispanic groups. Notably, in the NVVRS, it has been shown that Puerto Rican and Mexican veterans had

From the Center for Urban Epidemiologic Studies, New York Academy of Medicine, New York, NY (S.G., D.V., M.T., D.H.); Department of Epidemiology, Columbia University Mailman School of Public Health, New York, NY (S.G., D.V.); Department of Epidemiology, Johns Hopkins Bloomberg School of Public Health, Baltimore, MD (D.V.); Rutgers University, New Brunswick, NJ (D.H.); and National Crime Victims' Research and Treatment Center, Medical University of South Carolina, Charleston, SC (H.R., D.K.).

Address correspondence to: Sandro Galea, M.D., Dr.P.H., Center for Urban Epidemiologic Studies, New York Academy of Medicine, 1216 Fifth Avenue, New York, NY 10029, USA. Tel.: (212) 987-2560; Fax: (212) 8766220. E-mail: sgalea@nyam.org

Received September 17, 2003; accepted January 26, 2004. a higher risk for PTSD than other Hispanic veterans (4). Other studies have not found appreciable differences between racial/ethnic groups in either PTSD or post-traumatic stress symptoms after traumatic events or disasters $(6,7)$. Two recent meta-analyses of the risk factors for PTSD in trauma exposed adults suggested that race/ethnicity was a predictor of PTSD in some populations, but not in others $(8,9)$.

In the aftermath of the September 11, 2001 terrorist attacks, several studies provided population estimates of the incidence of PTSD both in New York City and in the US as a whole (10-12). Two of these population surveys assessing the psychological consequences of the September 11 attacks on the general US population did not document any racial/ethnic differences in the likelihood of PTSD or psychological symptoms after September $11(10,11)$. However, in two representative surveys of the New York City population conducted by our research group, we have shown that in the aftermath of the September 11 attacks in New York City, Hispanics were more likely to report symptoms consistent with PTSD than were other ethnic groups $(12,13)$.

This raises questions about the factors that may account for the observed higher incidence of PTSD among Hispanics in the aftermath of September 11 and whether specific Hispanic subgroups may disproportionately account for 


\section{Selected Abbreviations and Acronyms}

PTSD $=$ post-traumatic stress disorder

$\mathrm{SEP}=$ socio-economic position

$\mathrm{PR}=$ Puerto Rico

$\mathrm{DR}=$ Dominican Republic

WTC $=$ World Trade Center

NWS $=$ National Women's Study

$\mathrm{RDD}=$ random digit dial

this higher incidence. Also, in the aftermath of the September 11 attacks, a number of commentators have suggested that interventions to minimize the psychological consequences of disasters should be developed $(14,15)$. Such interventions may be more effective if they recognize, and target, the factors that explain the elevated risk of PTSD in specific groups. In this article we assess the ethnic differences in probable PTSD reported by respondents to a general population survey of residents of the New York City metropolitan area 6 months after September 11, 2001 and the potential explanations for these differences.

\section{METHODS}

\section{Sample}

Data for this analysis were from a random digit dial (RDD) household survey conducted between March 25 and June 25,2002 . The sampling frame for the survey included all adults in the following contiguous geographic areas: New York City and Nassau, Westchester, Suffolk, and Rockland counties in New York State; Hudson, Essex, Bergen, Passaic, Union, Middlesex, Monmouth, Morris, and Somerset counties in New Jersey, and Lower Fairfield County in Connecticut. All interviews were conducted by trained interviewers, in English, Spanish, Mandarin, and Cantonese, using translated and back-translated questionnaires and a computer-assisted telephone interview system. The overall cooperation rate (based on the sum of the number of completed interviews, quota outs, and screen-outs divided by the sum of completed interviews, quota outs, screen outs, refusals, and premature terminations) was $56 \%$ and the overall response rate (based on the sum of the number of completed and partial interviews divided by the sum of all numbers that were either eligible as residential telephone numbers or of unknown eligibility) was $34 \%$. We include with this manuscript an Appendix that discusses the implications of response rates in RDD sampling in general and the relevance of these response rates to this study in particular (see Appendix). Sampling weights were developed and applied to our data to correct potential selection bias related to the number of household telephones, persons in the household, and over-sampling. Further discussions of the methods and results from these surveys can also be found elsewhere $(12,13,16)$.

\section{Survey Instrument}

Respondents were asked questions using a structured interview which assessed the mental health consequences of natural disasters (17). We asked if the respondent was of Hispanic origin and then asked about respondent racial background by asking if respondents considered themselves White, Black, Asian, American Indian/Alaska Native, Native Hawaiian/Pacific Islander. We asked all respondents who considered themselves Hispanic what country their family was primarily from [e.g., Puerto Rico (PR), Dominican Republic (DR), etc.] using a list of predominantly Hispanic countries. Persons could report multiple race/ ethnicities. We asked about socio-economic position (SEP) by assessing household income, educational attainment, and employment. We inquired about other demographic characteristics (age, gender, marital status, social support) and about September 11 event-experiences [e.g., proximity to the World Trade Center (WTC) complex during the attacks, if the respondent had witnessed the attacks of September 11, etc.]. We also assessed whether the respondent experienced symptoms consistent with a panic attack in the first few hours after hearing about the September 11 attacks, based on DSM-IV criteria for panic attacks (18). Since surveys were conducted in English, Spanish, Mandarin, and Cantonese, we considered language of survey administration as a potential explanatory variable in the relation between race/ethnicity and PTSD.

We used the National Women's Study (NWS) PTSD module to assess PTSD symptoms since the September 11 terrorist attacks. The NWS PTSD module is a measure of PTSD that assesses the presence of criterion B, C, and D symptoms and determines content for content-specific symptoms (e.g., content of dreams or nightmares) if symptom presence is endorsed. We assessed probable PTSD that was related to the September 11 attacks based on the presence of necessary PTSD criterion B, C, and D symptoms since September 11. Participants were then required to report at least one re-experiencing symptom specific to the attack, at least three avoidance symptoms (content specific where relevant or since September 11), and two arousal symptoms (since September 11) for a diagnosis of probable PTSD related to the September 11 attacks since September 11.

The NWS PTSD module was validated in a field trial against the PTSD module of the Structured Clinical Interview for DSM-III-R (SCID) (19) administered by mental health professionals. In the field trial, instrument sensitivity 
was $99 \%$ and specificity was $79 \%$ when compared to SCID diagnosis (20). The NWS PTSD module has been used in a number of RDD studies throughout the United States (2123). Previous research using this measure among persons with a history of specific potentially traumatic events (e.g., rape, physical assault, or crime more generally) has shown that associations of these covariates with PTSD were highly consistent with those reported in other epidemiological studies that carefully assessed both history of events and PTSD, suggesting good construct validity for the NWS PTSD module (23).

\section{Analyses}

We assessed the prevalence of probable PTSD in the following racial/ethnic groups: Asian, Black, White, Hispanic, and Other races and found that the prevalence of probable PTSD was higher among Hispanics than among other racial/ethnic groups, consistent with previous reports $(12,13)$. Recognizing the potential of this sample to provide a more nuanced analysis of the prevalence of probable PTSD in different Hispanic subgroups, we assessed the prevalence of probable PTSD among Asian, Black, White, Other races, Dominicans, Puerto Ricans, and Other Hispanic reflecting the large number of persons with origins in the $\mathrm{DR}$ and $\mathrm{PR}$ in our survey. Documenting a comparable prevalence of probable PTSD among other racial/ethnic groups but a higher prevalence of probable PTSD among Puerto Ricans and Dominicans, we collapsed race/ethnicity into four key racial/ethnic groups of interest for the rest of the analyses: Non-Hispanics, Dominicans, Puerto Ricans, and Other Hispanic.

We considered various methods of dealing with missing data in order to present bivariate and multivariable analyses with comparable sample sizes to allow for cross-model comparison. Although there was relatively little missing data for the key variables, income data (important for assessing the role of SEP as a potential confounder) was missing in approximately $18 \%$ of cases. As such we conducted the analyses presented here: 1) restricted to persons on whom we had had complete data, including income data; 2) using several different data imputation methods, including median, mode, minimum, and maximum imputation for specific demographic groups; and 3) using a dummy variable for missing income data. Parameter estimates of interest in these three different sets of analyses did not differ appreciably, and we present all analyses here restricted to cases with no missing values on all variables but with a dummy variable representing missing income data.

We used two-tailed chi-square testing in bivariate analyses to assess the relations between key covariates and race/ ethnicity and between the key covariates and probable PTSD. Covariates that were associated both with race/
TABLE 1. Demographic characteristics of respondents surveyed 6 months after September 11, 2001 in the NYC metropolitan area compared to anticipated demographic characteristics based on the 2000 US Census $(n=2616)$

\begin{tabular}{|c|c|c|c|}
\hline Characteristics & $\begin{array}{l}\text { Weighted } \\
\text { percent } \\
\text { from sample }\end{array}$ & $\begin{array}{c}\text { Percent from } \\
2000 \text { US } \\
\text { Census }\end{array}$ & $\begin{array}{c}\text { Chi-square } \\
\text { p-value }\end{array}$ \\
\hline \multicolumn{4}{|l|}{ Age } \\
\hline $18-34$ & 38.2 & 32.1 & \multirow{3}{*}{0.309} \\
\hline $35-54$ & 39.3 & 39.6 & \\
\hline $55+$ & 22.5 & 28.3 & \\
\hline \multicolumn{4}{|l|}{ Gender } \\
\hline Male & 46.2 & 46.9 & \multirow[t]{2}{*}{0.892} \\
\hline Female & 53.8 & 53.1 & \\
\hline \multicolumn{4}{|l|}{ Race } \\
\hline White & 53.4 & 54.8 & \multirow[t]{5}{*}{0.812} \\
\hline African American & 16.4 & 16.5 & \\
\hline Asian & 5.4 & 7.7 & \\
\hline Hispanic & 21.0 & 18.5 & \\
\hline Other & 3.8 & 2.6 & \\
\hline \multicolumn{4}{|l|}{ Hispanic breakdown } \\
\hline Puerto Rican & 30.6 & 32.3 & \multirow[t]{3}{*}{0.934} \\
\hline Dominican & 16.1 & 15.5 & \\
\hline Other Hispanic & 53.3 & 52.2 & \\
\hline \multicolumn{4}{|l|}{ Income categories } \\
\hline$\$ 75,000+$ & 33.3 & 32.4 & \multirow[t]{3}{*}{0.553} \\
\hline$\$ 20,000-\$ 74,999$ & 49.8 & 46.4 & \\
\hline$<\$ 20,000$ & 16.9 & 21.3 & \\
\hline \multicolumn{4}{|l|}{ Marital status } \\
\hline Married & 50.8 & 52.6 & \multirow[t]{5}{*}{0.644} \\
\hline Separated & 2.3 & 3.3 & \\
\hline Divorced & 7.6 & 7.6 & \\
\hline Widowed & 4.6 & 7.4 & \\
\hline Never married & 34.6 & 29.0 & \\
\hline
\end{tabular}

ethnicity and probable PTSD at the $\mathrm{p}<0.1$ level were considered to be possible confounders of the relation between race/ethnicity and probable PTSD and were included in multivariate logistic regression analyses.

We used a series of multivariable models to assess the contribution of each of the covariates identified above to the relation between race/ethnicity and PTSD. Starting from a bivariate model with race/ethnicity as the only independent variable, we sequentially added each of the potential confounders identified above to the model. We determined the percent change in the race/ethnicity regression parameter in subsequent models to assess the contribution of each added covariate to the race/ethnicity-PTSD relation. In the final multivariable model we assessed interactions between each of the covariates and race/ethnicity. Interactions that were statistically significant at the $\mathrm{p}<$ 0.05 level were included in the final model. We present the two interactions that were statistically significant in separate final multivariable models. 
TABLE 2. Bivariate relations between race/ethnicity and socio-economic position, demographic variables, social support, and event exposures in a survey of residents of the New York City metropolitan area conducted 6 months after September 11, 2001

\begin{tabular}{|c|c|c|c|c|c|c|c|c|c|}
\hline \multirow[b]{2}{*}{ Characteristics } & \multicolumn{2}{|c|}{ Other races } & \multicolumn{2}{|c|}{ Other Hispanic } & \multicolumn{2}{|c|}{ Puerto Rican } & \multicolumn{2}{|c|}{ Dominican } & \multirow[b]{2}{*}{$\mathrm{p}$-value* } \\
\hline & $\mathrm{N}$ & $\%$ & $\mathrm{~N}$ & $\%$ & $\mathrm{~N}$ & $\%$ & $\mathrm{~N}$ & $\%$ & \\
\hline Total & 2157 & & 198 & & 180 & & 81 & & \\
\hline \multicolumn{10}{|l|}{ PTSD since September 11} \\
\hline No & 2002 & 94.9 & 181 & 93.9 & 156 & 86.8 & 70 & 85.7 & 0.008 \\
\hline Yes & 155 & 5.2 & 17 & 6.1 & 24 & 13.2 & 11 & 14.3 & \\
\hline \multicolumn{10}{|l|}{ Socioeconomic position } \\
\hline \multicolumn{10}{|l|}{ Income categories } \\
\hline$\$ 75,000+$ & 693 & 31.9 & 29 & 13.3 & 18 & 11.0 & 5 & 6.9 & $<0.001$ \\
\hline$\$ 20,000-\$ 74,999$ & 851 & 41.0 & 88 & 36.7 & 89 & 53.2 & 32 & 45.3 & \\
\hline$<\$ 20,000$ & 249 & 9.8 & 52 & 35.1 & 48 & 23.1 & 31 & 27.6 & \\
\hline Missing & 364 & 17.4 & 29 & 14.9 & 25 & 12.6 & 13 & 20.3 & \\
\hline \multicolumn{10}{|l|}{ Currently unemployed } \\
\hline No & 1387 & 63.6 & 139 & 70.3 & 98 & 57.2 & 45 & 57.5 & 0.281 \\
\hline Yes & 765 & 36.4 & 58 & 29.7 & 82 & 42.9 & 36 & 42.5 & \\
\hline \multicolumn{10}{|l|}{ Educational attainment } \\
\hline Graduate degree & 418 & 15.4 & 11 & 2.9 & 10 & 5.0 & 2 & 1.4 & $<0.001$ \\
\hline College degree & 744 & 31.2 & 43 & 15.8 & 33 & 19.8 & 10 & 17.9 & \\
\hline Some college & 403 & 21.5 & 40 & 17.8 & 41 & 26.7 & 19 & 25.4 & \\
\hline High school graduate/GED & 447 & 26.2 & 48 & 24.0 & 50 & 26.0 & 24 & 37.0 & \\
\hline$<$ High school graduate & 137 & 5.8 & 51 & 39.5 & 46 & 22.5 & 26 & 18.3 & \\
\hline \multicolumn{10}{|l|}{ Demographics } \\
\hline \multicolumn{10}{|l|}{ Age } \\
\hline $18-34$ & 684 & 33.5 & 106 & 61.8 & 66 & 42.3 & 44 & 62.9 & $<0.001$ \\
\hline $35-54$ & 899 & 40.5 & 72 & 30.8 & 78 & 43.4 & 28 & 30.1 & \\
\hline $55+$ & 574 & 26.0 & 20 & 7.4 & 36 & 14.3 & 9 & 7.0 & \\
\hline \multicolumn{10}{|l|}{ Gender } \\
\hline Male & 1024 & 46.6 & 101 & 49.3 & 61 & 35.0 & 32 & 49.3 & 0.204 \\
\hline Female & 1133 & 53.4 & 97 & 50.7 & 119 & 65.0 & 49 & 50.7 & \\
\hline \multicolumn{10}{|l|}{ Marital status } \\
\hline Married & 956 & 51.8 & 87 & 50.6 & 59 & 45.0 & 25 & 39.6 & 0.274 \\
\hline Divorced/Separated/Widowed & 400 & 14.7 & 27 & 10.7 & 47 & 14.3 & 24 & 24.8 & \\
\hline Never married & 722 & 30.8 & 74 & 31.9 & 66 & 37.4 & 31 & 34.3 & \\
\hline Unmarried couple & 71 & 2.7 & 9 & 6.8 & 8 & 3.4 & 1 & 1.3 & \\
\hline Live below 14th St & & & & & & & & & \\
\hline No & 1653 & 98.4 & 165 & 99.1 & 106 & 96.7 & 54 & 97.1 & $<0.001$ \\
\hline Yes & 504 & 1.6 & 33 & 0.9 & 74 & 3.3 & 27 & 2.9 & \\
\hline Social support & & & & & & & & & \\
\hline Social support categories & & & & & & & & & \\
\hline High & 900 & 42.7 & 54 & 24.4 & 60 & 36.8 & 20 & 19.7 & $<0.001$ \\
\hline Medium & 642 & 31.0 & 53 & 29.3 & 52 & 30.0 & 23 & 36.9 & \\
\hline Low & 615 & 26.3 & 91 & 46.4 & 68 & 33.3 & 38 & 43.4 & \\
\hline Stressors & & & & & & & & & \\
\hline Lifetime traumatic experiences be & & & & & & & & & \\
\hline 0 & 581 & 27.3 & 52 & 29.8 & 58 & 28.9 & 33 & 34.1 & 0.591 \\
\hline 1 & 589 & 29.1 & 54 & 29.2 & 60 & 38.6 & 24 & 27.6 & \\
\hline $2-3$ & 604 & 27.4 & 54 & 28.7 & 32 & 18.1 & 13 & 20.6 & \\
\hline $4+$ & 382 & 16.2 & 38 & 12.3 & 30 & 14.5 & 11 & 17.7 & \\
\hline Stressors 12 months before Septen & & & & & & & & & \\
\hline 0 & 1257 & 58.6 & 119 & 64.8 & 97 & 54.2 & 55 & 63.5 & 0.659 \\
\hline 1 & 576 & 27.4 & 43 & 25.2 & 51 & 30.6 & 14 & 21.8 & \\
\hline $2+$ & 324 & 14.0 & 36 & 10.0 & 32 & 15.1 & 12 & 14.8 & \\
\hline Event exposures & & & & & & & & & \\
\hline Peri-event panic attack & & & & & & & & & \\
\hline No & 1881 & 88.3 & 170 & 89.2 & 131 & 70.9 & 56 & 61.2 & $<0.001$ \\
\hline Yes & 276 & 11.7 & 28 & 10.8 & 49 & 29.1 & 25 & 38.8 & \\
\hline Friend or relative killed & & & & & & & & & \\
\hline No & 1837 & 83.0 & 177 & 91.3 & 154 & 88.8 & 70 & 88.2 & 0.094 \\
\hline Yes & 320 & 17.0 & 21 & 8.7 & 26 & 11.2 & 11 & 11.8 & \\
\hline
\end{tabular}


TABLE 2. Continued

\begin{tabular}{|c|c|c|c|c|c|c|c|c|c|}
\hline \multirow[b]{2}{*}{ Characteristics } & \multicolumn{2}{|c|}{ Other races } & \multicolumn{2}{|c|}{ Other Hispanic } & \multicolumn{2}{|c|}{ Puerto Rican } & \multicolumn{2}{|c|}{ Dominican } & \multirow[b]{2}{*}{ p-value* } \\
\hline & $\mathrm{N}$ & $\%$ & $\mathrm{~N}$ & $\%$ & $\mathrm{~N}$ & $\%$ & $\mathrm{~N}$ & $\%$ & \\
\hline \multicolumn{10}{|c|}{ Lost possessions } \\
\hline $\mathrm{No}$ & 2072 & 97.6 & 189 & 98.2 & 169 & 95.5 & 80 & 99.6 & 0.237 \\
\hline Yes & 83 & 2.4 & 9 & 1.8 & 10 & 4.5 & 1 & 0.4 & \\
\hline \multicolumn{10}{|c|}{ Involved in rescue effort } \\
\hline No & 1922 & 90.7 & 174 & 90.8 & 164 & 89.1 & 74 & 91.1 & 0.978 \\
\hline Yes & 233 & 9.3 & 24 & 9.2 & 16 & 10.9 & 7 & 8.9 & \\
\hline
\end{tabular}

*Two-tailed chi-squared p-value.

\section{RESULTS}

Out of 2705 persons eligible for this analysis, we restricted the dataset to 2616 persons on whom we had complete data for all variables except income; we used a dummy variable to represent missing income data to include these persons in all analyses. Table 1 shows the demographic characteristics of the respondents included in these analyses and of residents of the NYC metropolitan area, according to the US Census, to show comparability of the sample. The population sampled is statistically comparable to the anticipated data from the US Census and there were no appreciable differences between the population sampled and the underlying population.

Overall, 459 (21.0\%) respondents identified themselves as Hispanic. 3.3\% of the sample reported being of multiple race/ethnicities. The prevalence of probable PTSD among Hispanics in the sample was $9.6 \%$, which was higher than that in other racial/ethnic groups (Black 7.0\%, White 4.6\%, Asian 4.4\%, Other 6.2\%). Separating the Hispanic group into its three largest constituent groups (persons from the DR, PR, or other countries) showed that the highest prevalence of probable PTSD was in persons from the DR (14.3\%) and PR (13.2\%); the prevalence of probable PTSD among Hispanics from other countries $(6.1 \%)$ was not appreciably different than that for persons in other racial groups. The prevalence of probable PTSD in the final grouping that was used for the rest of these analyses was: non-Hispanics (5.2\%), Dominicans (14.3\%), Puerto Ricans (13.2\%), and other Hispanics (6.1\%). We note that persons with multiple race/ethnicities who reported that they were Hispanic were analyzed as such (within categories of PR, DR, and other Hispanic), and persons who did not report Hispanicity as one of their ethnicities were considered non-Hispanics.

Table 2 shows bivariate associations between key covariates and race/ethnicity in the final grouping discussed above. Variables that were significantly associated with race/ethnicity were: household income $(\mathrm{p}<0.001)$, educational attainment $(p<0.001)$, age $(p<0.001)$, living south of $14^{\text {th }}$ street on September $11(\mathrm{p}<0.001)$, social support $(p<0.001)$, having experienced a peri-event panic attack $(p<0.001)$, and having had a friend or relative killed on September $11(\mathrm{p}=0.094)$. Table 3 shows bivariate associations between key covariates and probable PTSD. Variables that were significantly associated with probable PTSD were: income $(p=0.003)$, age $(p=0.095)$, marital status $(p=$ $0.012)$, living south of $14^{\text {th }}$ street on September 11 ( $p<$ $0.001)$, social support $(\mathrm{p}=0.003)$, prior exposure to traumatic events ( $\mathrm{p}<0.001$ ), recent exposure to stressors ( $\mathrm{p}<$ 0.001 ), having experienced a peri-event panic attack ( $\mathrm{p}<$ 0.001 ), having had a friend or relative killed on September $11(\mathrm{p}=0.001)$, having lost possessions in the attacks $(\mathrm{p}<$ 0.001 ), and having been involved in the rescue effort $(p=0.003)$. Language of survey administration was not significantly associated with likelihood of PTSD.

Variables that were associated with both probable PTSD and with race/ethnicity in bivariate analyses and as such were included in the final multivariable model were: income, age, having lived south of $14^{\text {th }}$ street, social support, experiencing a peri-event panic attack, and having had a friend or relative killed in the attacks (Table 4). In the final multivariable model, Dominicans were 1.35 times more likely [95\% confidence interval (CI), 0.49-3.77] and Puerto Ricans were 1.51 times more likely (95\% CI, 0.59-3.83) to have symptoms consistent with probable PTSD. In the final multivariable model, the covariates added had accounted for $73.5 \%$ and $60.2 \%$ of the relative increase in PTSD among Dominicans and Puerto Ricans respectively. Interaction terms that were significant in the final multivariable model were the interaction between race/ethnicity and social support and between race/ethnicity and the experience of a peri-event panic attack. Table 5 shows the final multivariable model with the interaction terms added separately. As shown in Model I, among persons who experienced a peri-event panic attack, the odds ratio of probable PTSD was 8.41 for non-Hispanics, 4.57 for other Hispanics, 4.26 for Puerto Ricans, and 11.02 for Dominicans, compared to 
TABLE 3. Bivariate relations between probable PTSD and socio-economic position, demographic variables, social support, and event exposures in a survey of residents of the New York City metropolitan area conducted 6 months after September 11, 2001

\begin{tabular}{|c|c|c|c|c|c|}
\hline \multirow[b]{2}{*}{ Characteristics } & \multicolumn{2}{|c|}{ Total sample } & \multicolumn{3}{|c|}{ Probable PTSD since September 11} \\
\hline & $\mathrm{N}$ & $\%$ & N PTSD & $\%$ PTSD & p-value* \\
\hline Total & 2616 & 100.0 & 207 & 6.1 & \\
\hline \multicolumn{6}{|l|}{ Race/Ethnicity } \\
\hline \multicolumn{6}{|l|}{ Final race categories } \\
\hline Other races & 2157 & 79.0 & 155 & 5.2 & 0.008 \\
\hline Other Hispanic & 198 & 11.2 & 17 & 6.1 & \\
\hline Puerto Rican & 180 & 6.4 & 24 & 13.2 & \\
\hline Dominican & 81 & 3.4 & 11 & 14.3 & \\
\hline \multicolumn{6}{|l|}{ Socioeconomic position } \\
\hline \multicolumn{6}{|l|}{ Income categories } \\
\hline$\$ 75,000+$ & 745 & 27.6 & 53 & 4.3 & 0.003 \\
\hline$\$ 20,000-\$ 74,999$ & 1060 & 41.4 & 86 & 6.4 & \\
\hline$<\$ 20,000$ & 380 & 14.1 & 44 & 11.8 & \\
\hline Missing & 431 & 16.9 & 24 & 3.5 & \\
\hline \multicolumn{6}{|l|}{ Currently unemployed } \\
\hline No & 1669 & 63.7 & 124 & 5.6 & 0.270 \\
\hline Yes & 941 & 36.3 & 83 & 7.1 & \\
\hline \multicolumn{6}{|l|}{ Educational attainment } \\
\hline Graduate degree & 441 & 12.9 & 40 & 5.0 & 0.452 \\
\hline College degree & 830 & 28.3 & 62 & 6.0 & \\
\hline Some college & 503 & 21.6 & 38 & 5.9 & \\
\hline High school graduate/GED & 569 & 26.3 & 32 & 5.3 & \\
\hline$<$ High school graduate & 260 & 11.0 & 34 & 10.1 & \\
\hline \multicolumn{6}{|l|}{ Demographics } \\
\hline \multicolumn{6}{|l|}{ Age } \\
\hline $18-34$ & 900 & 38.2 & 72 & 6.3 & 0.095 \\
\hline $35-54$ & 1077 & 39.3 & 102 & 7.1 & \\
\hline $55+$ & 639 & 22.5 & 33 & 4.0 & \\
\hline \multicolumn{6}{|l|}{ Gender } \\
\hline Male & 1218 & 46.2 & 85 & 5.5 & 0.390 \\
\hline Female & 1398 & 53.8 & 122 & 6.6 & \\
\hline \multicolumn{6}{|l|}{ Marital status } \\
\hline Married & 1127 & 50.8 & 78 & 5.0 & 0.012 \\
\hline Divorced/Separated/Widowed & 498 & 14.6 & 43 & 9.5 & \\
\hline Never married & 893 & 31.5 & 72 & 5.3 & \\
\hline Unmarried couple & 89 & 3.2 & 13 & 15.8 & \\
\hline \multicolumn{6}{|l|}{ Live below 14th St } \\
\hline No & 1978 & 98.3 & 122 & 6.0 & $<0.001$ \\
\hline Yes & 638 & 1.7 & 85 & 12.4 & \\
\hline \multicolumn{6}{|l|}{ Social support } \\
\hline \multicolumn{6}{|l|}{ Social support categories } \\
\hline High & 1034 & 39.5 & 52 & 3.6 & 0.003 \\
\hline Medium & 770 & 30.9 & 59 & 7.1 & \\
\hline Low & 812 & 29.6 & 96 & 8.4 & \\
\hline \multicolumn{6}{|l|}{ Stressors } \\
\hline Lifetime stressors before Septembe & & & & & \\
\hline 0 & 724 & 27.9 & 31 & 2.3 & $<0.001$ \\
\hline 1 & 727 & 29.7 & 44 & 4.0 & \\
\hline $2-3$ & 703 & 26.7 & 64 & 8.2 & \\
\hline $4+$ & 461 & 15.7 & 68 & 13.1 & \\
\hline Life stressors 12 months before Se & & & & & \\
\hline 0 & 1528 & 59.2 & 75 & 3.4 & $<0.001$ \\
\hline 1 & 684 & 27.2 & 72 & 9.7 & \\
\hline $2+$ & 404 & 13.6 & 60 & 10.6 & \\
\hline Event experiences & & & & & \\
\hline Peri-event panic attack & & & & & \\
\hline No & 2238 & 86.4 & 99 & 3.6 & $<0.001$ \\
\hline Yes & 378 & 13.6 & 108 & 22.2 & \\
\hline
\end{tabular}


TABLE 3. Continued

\begin{tabular}{|c|c|c|c|c|c|}
\hline \multirow[b]{2}{*}{ Characteristics } & \multicolumn{2}{|c|}{ Total sample } & \multicolumn{3}{|c|}{ Probable PTSD since September 11} \\
\hline & $\mathrm{N}$ & $\%$ & N PTSD & $\%$ PTSD & p-value* \\
\hline \multicolumn{6}{|c|}{ Friend or relative killed } \\
\hline No & 2238 & 84.5 & 159 & 5.1 & 0.001 \\
\hline Yes & 378 & 15.5 & 48 & 11.6 & \\
\hline \multicolumn{6}{|c|}{ Lost possessions } \\
\hline No & 2510 & 97.6 & 178 & 5.7 & $<0.001$ \\
\hline Yes & 103 & 2.4 & 29 & 21.5 & \\
\hline \multicolumn{6}{|c|}{ Involved in rescue effort } \\
\hline No & 2334 & 90.6 & 164 & 5.5 & 0.003 \\
\hline Yes & 280 & 9.4 & 43 & 11.9 & \\
\hline
\end{tabular}

*Two-tailed chi-squared p-value.

non-Hispanics who did not experience a peri-event panic attack. As shown in Model II, among persons with low social support, the odds ratio of probable PTSD was 2.59 for nonHispanics, 0.84 for other Hispanics, 3.90 for Puerto Ricans, and 0.16 for Dominicans compared to non-Hispanics with high social support.

\section{DISCUSSION}

Using data from a representative population survey of the New York City metropolitan area we found that Dominicans and Puerto Ricans were more likely to report symptoms consistent with probable PTSD than were other Hispanics or non-Hispanics. Variables including SEP, social support, exposure to the September 11 attacks, and peri-event emotional reactions, accounted for approximately $60 \%$ to $74 \%$ of the observed higher prevalence of probable PTSD in these groups. Experiencing a peri-event panic attack was a strong risk factor for Dominicans while low social support was a strong risk factor for Puerto Ricans.

The underlying finding in this study, namely that Hispanics are more likely to report probable PTSD is consistent with findings from some $(3,24)$, but not all $(2,7)$, studies that have explored the issue of racial/ethnic differences in risk for PTSD. A number of covariates partly explained the higher prevalence of probable PTSD among Hispanics in our sample. Adjustment for SEP accounted for up to $17.7 \%$ of the higher risk of probable PTSD among Puerto Ricans and up to $14.6 \%$ among Dominicans. The fundamental role that SEP may play in confounding the relation between race/ ethnicity and health has been well documented although most of the work in this regard has focused on physical rather than mental health (25-27). The differential role of SEP between different minority groups (recognizing that Blacks, typically the racial group with the lowest SEP, did not have a higher prevalence of PTSD than did other groups) suggests that SEP is only partly responsible for the observed ethnic differences in PTSD. In contrast to the
NVVRS (3), we found that the extent of exposure to the traumatic event (i.e., combat in the NVVRS, and the September 11 attacks in our study) partly explained the higher prevalence of PTSD reported by Hispanics in our study; this difference was probably attributable to a disproportionately high density of Hispanics living close to the WTC in NYC.

One of the first analyses to address ethnic differences in PTSD risk suggested that low social support and acculturation were responsible for the high risk of PTSD among Hispanics (28). This partly concurs with our observation that social support was a particularly important determinant of differences in PTSD risk between groups of Hispanics. However, we failed to observe a difference in incidence of probable PTSD between Hispanics who were interviewed in English or in Spanish in our study, suggesting that acculturation may play a lesser role in the post-September 11 context. An analysis of NVVRS data including Hispanic and non-Hispanic veterans concurred that acculturation was unlikely to explain the observed higher prevalence of PTSD among Hispanic Vietnam veterans (4). Consistent with our observation that Puerto Ricans (together with Dominicans) had the highest risk of PTSD after September 11, the NVVRS analysis found that Puerto Rican and Mexican veterans had a higher risk for PTSD than other Hispanic veterans (4). There were too few Mexican Hispanics in our sample to reliably assess the prevalence of probable PTSD in that group.

We documented an important role of peri-event emotional reactions in the differential risk of development of PTSD between subgroups of Hispanics; in particular, perievent panic attacks were more important for persons of Dominican descent than for other Hispanics. Other studies have shown that peri-event panic attacks may play an important etiologic role in the development of PTSD $(29,30)$. "Ataques de nervios," frequently described as a loss of control in emotional expressions, sensations, and actions in Hispanics, have been shown to be associated with panic disorder, post-traumatic stress, and depression (31-35). 
TABLE 4. Multivariable models describing the relation between race/ethnicity and probable PTSD in a survey of residents of the New York City metropolitan area conducted 6 months after September 11, $2001(\mathrm{n}=2616)^{*}$

\begin{tabular}{|c|c|c|c|c|c|c|c|c|c|c|c|c|c|c|}
\hline \multirow[b]{2}{*}{ Characteristics } & \multicolumn{2}{|c|}{ Model I } & \multicolumn{2}{|c|}{ Model II } & \multicolumn{2}{|c|}{ Model III } & \multicolumn{2}{|c|}{ Model IV } & \multicolumn{2}{|c|}{ Model V } & \multicolumn{2}{|c|}{ Model VI } & \multicolumn{2}{|c|}{ Model VII } \\
\hline & OR & $95 \% \mathrm{CI}$ & OR & $95 \% \mathrm{CI}$ & OR & $95 \% \mathrm{CI}$ & OR & $95 \% \mathrm{CI}$ & OR & $95 \% \mathrm{CI}$ & OR & $95 \% \mathrm{CI}$ & OR & $95 \% \mathrm{CI}$ \\
\hline \multicolumn{15}{|l|}{ Race/Ethnicity } \\
\hline Other races & 1.00 & - & 1.00 & - & 1.00 & - & 1.00 & - & 1.00 & - & 1.00 & - & 1.00 & - \\
\hline Other Hispanic & 1.20 & $0.48-3.00$ & 0.92 & $0.37-2.27$ & 0.87 & $0.35-2.15$ & 0.88 & $0.36-2.18$ & 0.78 & $0.31-1.99$ & 0.95 & $0.35-2.59$ & 0.99 & $0.37-2.68$ \\
\hline Puerto Rican & 2.79 & $1.41-5.55$ & 2.33 & $1.17-4.66$ & 2.22 & $1.12-4.41$ & 2.20 & $1.10-4.38$ & 2.19 & $1.09-4.38$ & 1.50 & $0.62-3.62$ & 1.51 & $0.59-3.83$ \\
\hline Dominican & 3.08 & $1.05-9.08$ & 2.55 & $0.89-7.27$ & 2.39 & $0.84-6.80$ & 2.37 & $0.83-6.79$ & 2.06 & $0.71-6.03$ & 1.35 & $0.49-3.76$ & 1.35 & $0.49-3.77$ \\
\hline \multirow{2}{*}{\multicolumn{15}{|c|}{$\begin{array}{l}\text { Socioeconomic position } \\
\text { Income categories }\end{array}$}} \\
\hline & & & & & & & & & & & & & \multicolumn{2}{|c|}{ Income categories } \\
\hline$\$ 75,000+$ & & & 1.00 & - & 1.00 & - & 1.00 & - & 1.00 & - & 1.00 & - & 1.00 & - \\
\hline$\$ 20,000-\$ 74,999$ & & & 1.40 & $0.82-2.39$ & 1.50 & $0.87-2.56$ & 1.50 & $0.88-2.57$ & 1.36 & $0.80-2.31$ & 1.29 & $0.74-2.25$ & 1.37 & $0.78-2.40$ \\
\hline$<\$ 20,000$ & & & 2.61 & $1.32-5.16$ & 2.89 & $1.45-5.74$ & 2.87 & $1.44-5.71$ & 2.46 & $1.22-4.94$ & 2.16 & $1.01-4.63$ & 2.33 & $1.06-5.12$ \\
\hline Missing & & & 0.76 & $0.38-1.56$ & 0.83 & $0.41-1.67$ & 0.83 & $0.41-1.67$ & 0.76 & $0.38-1.54$ & 0.76 & $0.37-1.57$ & 0.76 & $0.37-1.56$ \\
\hline \multicolumn{15}{|l|}{ Demographics } \\
\hline \multicolumn{15}{|l|}{ Age } \\
\hline $18-34$ & & & & & 1.00 & - & 1.00 & - & 1.00 & - & 1.00 & - & 1.00 & - \\
\hline $35-54$ & & & & & 1.30 & $0.79-2.14$ & 1.30 & $0.79-2.14$ & 1.21 & $0.73-2.00$ & 1.33 & $0.76-2.31$ & 1.34 & $0.76-2.34$ \\
\hline $55+$ & & & & & 0.69 & $0.38-1.25$ & 0.69 & $0.38-1.25$ & 0.62 & $0.34-1.15$ & 0.76 & $0.39-1.47$ & 0.74 & $0.38-1.45$ \\
\hline \multicolumn{15}{|l|}{ Live below 14th St } \\
\hline No & & & & & & & 1.00 & - & 1.00 & - & 1.00 & - & 1.00 & - \\
\hline Yes & & & & & & & 1.92 & $1.33-2.77$ & 1.90 & $1.32-2.75$ & 1.91 & $1.30-2.80$ & 1.99 & $1.34-2.97$ \\
\hline \multicolumn{15}{|l|}{ Social support } \\
\hline \multicolumn{15}{|c|}{ Social support categories } \\
\hline High & & & & & & & & & 1.00 & - & 1.00 & - & 1.00 & - \\
\hline Medium & & & & & & & & & 1.89 & $1.06-3.35$ & 1.56 & $0.83-2.93$ & 1.59 & $0.84-3.03$ \\
\hline Low & & & & & & & & & 2.23 & $1.26-3.95$ & 1.80 & $1.00-3.25$ & 1.95 & $1.07-3.53$ \\
\hline \multicolumn{15}{|l|}{ Event experiences } \\
\hline \multicolumn{15}{|c|}{ Peri-event panic attack } \\
\hline No & & & & & & & & & & & 1.00 & - & 1.00 & - \\
\hline Yes & & & & & & & & & & & 6.38 & $3.84-10.62$ & 5.95 & $3.52-10.06$ \\
\hline \multicolumn{15}{|l|}{ Friend or relative killed } \\
\hline No & & & & & & & & & & & & & 1.00 & - \\
\hline Yes & & & & & & & & & & & & & 2.53 & $1.34-4.77$ \\
\hline
\end{tabular}

*Characteristics that were differentially distributed among racial groups and were significantly associated with probable PTSD in bivariate analysis were considered in this analysis. $\mathrm{OR}$, odds ratio; $\mathrm{CI}$, confidence intervals. 
TABLE 5. Final models describing the relation between race/ethnicity and probable PTSD in a survey of residents of the New York City metropolitan area conducted 6 months after September 11, 2001 including interaction terms $(\mathrm{n}=2616)$

\begin{tabular}{|c|c|c|c|c|c|c|c|c|}
\hline Characteristics & Beta & OR* & $95 \% \mathrm{CI}$ & Wald p-value & Beta & OR & $95 \% \mathrm{CI}$ & Wald $\mathrm{p}$-value \\
\hline \multicolumn{9}{|l|}{ Race/Ethnicity } \\
\hline Other races & 0.00 & 1.00 & - & \multirow[t]{4}{*}{$\mathrm{n} / \mathrm{a}$} & 0.00 & 1.00 & - & \multirow[t]{4}{*}{$\mathrm{n} / \mathrm{a}$} \\
\hline Other Hispanic & 0.27 & $\mathrm{n} / \mathrm{a}$ & $\mathrm{n} / \mathrm{a}$ & & 0.35 & $\mathrm{n} / \mathrm{a}$ & $\mathrm{n} / \mathrm{a}$ & \\
\hline Puerto Rican & 1.45 & $\mathrm{n} / \mathrm{a}$ & $\mathrm{n} / \mathrm{a}$ & & 0.92 & $\mathrm{n} / \mathrm{a}$ & $\mathrm{n} / \mathrm{a}$ & \\
\hline Dominican & -0.10 & $\mathrm{n} / \mathrm{a}$ & $\mathrm{n} / \mathrm{a}$ & & -2.21 & $\mathrm{n} / \mathrm{a}$ & $\mathrm{n} / \mathrm{a}$ & \\
\hline \multicolumn{9}{|l|}{ Socioeconomic position } \\
\hline \multicolumn{9}{|l|}{ Income categories } \\
\hline$\$ 75,000+$ & 0.00 & 1.00 & - & \multirow{4}{*}{0.039} & 0.00 & 1.00 & - & \multirow{4}{*}{0.060} \\
\hline$\$ 20,000-\$ 74,999$ & 0.26 & 1.30 & $0.74-2.29$ & & 0.24 & 1.27 & $0.72-2.26$ & \\
\hline$<\$ 20,000$ & 0.84 & 2.31 & $1.06-4.99$ & & 0.79 & 2.19 & $1.05-4.59$ & \\
\hline Missing & -0.33 & 0.72 & $0.34-1.52$ & & -0.25 & 0.78 & $0.38-1.62$ & \\
\hline \multicolumn{9}{|l|}{ Demographics } \\
\hline \multicolumn{9}{|l|}{ Age } \\
\hline $18-34$ & 0.00 & 1.00 & - & \multirow[t]{3}{*}{0.089} & 0.00 & 1.00 & - & \multirow[t]{3}{*}{0.190} \\
\hline $35-54$ & 0.28 & 1.32 & $0.76-2.29$ & & 0.21 & 1.24 & $0.73-2.11$ & \\
\hline $55+$ & -0.38 & 0.68 & $0.35-1.36$ & & -0.32 & 0.72 & $0.37-1.41$ & \\
\hline \multicolumn{9}{|l|}{ Live below 14th St } \\
\hline No & 0.00 & 1.00 & - & \multirow[t]{2}{*}{0.003} & 0.00 & 1.00 & - & \multirow[t]{2}{*}{$<0.001$} \\
\hline Yes & 0.63 & 1.87 & $1.25-2.81$ & & 0.79 & 2.20 & $1.48-3.28$ & \\
\hline \multicolumn{9}{|l|}{ Social support } \\
\hline Social support categories & & & & \multirow{4}{*}{0.058} & & & & \multirow{4}{*}{$\mathrm{n} / \mathrm{a}$} \\
\hline High & 0.00 & 1.00 & - & & 0.00 & 1.00 & - & \\
\hline Medium & 0.48 & 1.62 & $0.88-2.99$ & & 0.33 & $\mathrm{n} / \mathrm{a}$ & $\mathrm{n} / \mathrm{a}$ & \\
\hline Low & 0.71 & 2.03 & $1.13-3.63$ & & 0.95 & $\mathrm{n} / \mathrm{a}$ & $\mathrm{n} / \mathrm{a}$ & \\
\hline \multicolumn{9}{|l|}{ Event experiences } \\
\hline \multicolumn{9}{|l|}{ Peri-event panic attack } \\
\hline No & 0.00 & 1.00 & - & \multirow[t]{2}{*}{$\mathrm{n} / \mathrm{a}$} & 0.00 & 1.00 & - & \multirow[t]{2}{*}{$<0.001$} \\
\hline Yes & 2.13 & $\mathrm{n} / \mathrm{a}$ & $\mathrm{n} / \mathrm{a}$ & & 1.81 & 6.13 & $3.67-10.23$ & \\
\hline \multicolumn{9}{|l|}{ Friend or relative killed } \\
\hline No & 0.00 & 1.00 & - & \multirow[t]{2}{*}{0.002} & 0.00 & 1.00 & - & 0.003 \\
\hline Yes & 1.00 & 2.71 & $1.45-5.07$ & & 0.88 & 2.41 & $1.35-4.30$ & \\
\hline Interactions & & & & & & & & \\
\hline Panic and race & & & & & & & & \\
\hline Panic $\times$ other Hispanic & -0.88 & $\mathrm{n} / \mathrm{a}$ & $\mathrm{n} / \mathrm{a}$ & 0.029 & & & & \\
\hline Panic $\times$ Puerto Rican & -2.13 & $\mathrm{n} / \mathrm{a}$ & $\mathrm{n} / \mathrm{a}$ & & & & & \\
\hline Panic $\times$ Dominican & 0.37 & $\mathrm{n} / \mathrm{a}$ & $\mathrm{n} / \mathrm{a}$ & & & & & \\
\hline Social support and race & & & & & & & & \\
\hline Low support $\times$ other Hispanic & & & & & -1.47 & $\mathrm{n} / \mathrm{a}$ & $\mathrm{n} / \mathrm{a}$ & $<0.001$ \\
\hline Low support $\times$ Puerto Rican & & & & & -0.51 & $\mathrm{n} / \mathrm{a}$ & $\mathrm{n} / \mathrm{a}$ & \\
\hline Low support $\times$ Dominican & & & & & -0.56 & $\mathrm{n} / \mathrm{a}$ & $\mathrm{n} / \mathrm{a}$ & \\
\hline Medium support $\times$ other Hispanic & & & & & 0.56 & $\mathrm{n} / \mathrm{a}$ & $\mathrm{n} / \mathrm{a}$ & \\
\hline Medium support $\times$ Puerto Rican & & & & & -1.03 & $\mathrm{n} / \mathrm{a}$ & $\mathrm{n} / \mathrm{a}$ & \\
\hline Medium support $\times$ Dominican & & & & & 3.73 & $\mathrm{n} / \mathrm{a}$ & $\mathrm{n} / \mathrm{a}$ & \\
\hline
\end{tabular}

* Odds ratios are not given for variables where interactions are present since these odds ratios are uninterpretable. Model parameters must be used to determine relative odds of the relation between specific variables and the outcome. For example, the odds ratio comparing persons from Puerto Rico who had a peri-event panic attack and non-Hispanics who did not would be $\exp (1.45+2.13-2.13)=4.26$. A few key odds ratios are as follows: Dominicans who had a peri-event panic attack had an odds ratio of 11.02 and non-Hispanics who had a peri-event panic attack had an odds ratio of 8.41 , both compared to non-Hispanics who did not report a peri-event panic attack. Persons from Puerto Rico who had low social support had an odds ratio of 3.90, persons from the Dominican Republic with low social support had an odds ratio of 0.16 , and non-Hispanics with low social support had an odds ratio of 2.59 , both compared to non-Hispanics with high social support.

These findings, taken together, suggest that differences in cultural or subjective factors, or emotional expression, may explain some of the differences we observed in the role of peri-event panic between Dominicans and Puerto Ricans in this sample.

The inferences that can be drawn from our results may be limited by a number of factors. There are several other variables that we did not measure in this survey that could account for some of the racial/ethnic disparities in probable PTSD prevalence. For example, our survey did not include a detailed past psychological history, limiting the conclusions we can draw from respondents' reports of previous mental or emotional problems. We also did not measure factors such as acculturation, experiences of racism, or place of 
birth of respondents, factors that have been considered in the past as potential mediators of the epidemiologic relation between race/ethnicity and PTSD. It is plausible that these and other variables partly account for the relation between race/ethnicity and PTSD in other urban contexts. This necessarily limits the inference that can be drawn from this analysis about the role of race/ethnicity in mental health. Also, the interaction terms discussed here rely on small cell sample sizes and as such, must be interpreted with caution.

It is possible that our sample introduced bias that was not accounted for by our analytic strategy. This is unlikely given the representativeness of the sample and the consistence between many of the analysis previously documented from this sample with those reported in other epidemiological studies that assessed PTSD after disaster $(12,13,16)$. In order to ensure comparability across multivariable models we restricted the sample size for all bivariate and multivariable analyses to the same sub-sample of persons. Although we accounted for missing data on income using multiple analytic techniques and sensitivity analyses did not suggest substantial differences in the conclusions drawn here, it remains possible that non-response bias accounted for some of our observed associations. Some of the conclusions drawn in the manuscript are limited by the modeling technique used. In order to best understand the range of variables that may be important in explaining the race/ethnicity-PTSD relation we included all measured variables that may statistically explain this relation (i.e., variables that were associated with both race/ethnicity and with probable PTSD in bivariate analyses). We note that all the variables included in the final model are important and contribute to the relation between race/ethnicity and probable PTSD in this sample.

In the particular context of Dominicans, we note that the crash of flight 587 bound to the DR and carrying mostly Dominicans, on November 12, 2001, could have had a bearing on some of the observations in this study. Although we did not ask specific questions about the crash of flight 587 in our survey, we asked about other prominent recent stressors and these did not play a role in the higher prevalence of PTSD among Dominicans documented in this study.

\section{CONCLUSIONS}

We observed in our study of the general population of the NYC metropolitan area after September 11 that specific socio-demographic variables, event exposures, social support, and peri-event emotional reactions may explain differences in PTSD risk after a disaster between Hispanic subgroups and non-Hispanics and that the latter two factors may be important determinants of differential risk among Hispanic subgroups.

We would like to acknowledge the contributions of Jennifer Ahern to the study discussed here. We would also like to thank Dr. Michael Bucuvalas, Dr. Bruce Link, and two anonymous reviewers for insightful comments that contributed immensely to the final version of this manuscript. We are indebted to those who participated in this study.

\section{APPENDIX \\ On the Use of Telephone Surveys in Epidemiology}

There is growing evidence of the validity of using random digit dial telephone surveys in epidemiologic assessments. One assessment conducted both in-person and telephone interview surveys simultaneously in the same area using the same interview schedule (36). This study, consistent with other work $(37,38)$, found that telephone respondents tended to be younger, better educated, and more likely to be white than in-person respondents. However, and most importantly, the same assessment showed that there were no substantial differences in accuracy of self-reported conditions or in health utilization questions. In fact, the assessment showed that internal consistency between responses was higher in the telephone surveys than in the in-person surveys. This study also showed that telephone surveys were appreciably cheaper to conduct than in-person surveys. A similar study (37), compared telephone and in-person surveys of physical morbidity using random assignment to one of the two methods. That study found no statistically significant differences between the two interview methods for overall assessment of health status, illnesses reported for the previous four months, or reports of hospitalization. Specific to mental health, several studies have shown that telephone assessment of axis I disorders (including depression and anxiety disorders) produced nearly identical results to inperson assessments using a variety of instruments $(39,40)$. Another study using both a clinical in-person assessment and a telephone survey found similarity in reporting of trauma and PTSD suggesting appropriateness of telephone methodology for collecting data relevant to this study (41). Importantly, telephone survey methods have become the standard method for the Behavioral Risk Factor Surveillance System (BRFSS), the national risk factor surveillance system. The BRFSS has been invaluable in providing assessments of ongoing trends in self-reported health and risk behaviors and its methods have been emulated in many local public health jurisdictions (42-44). In a recent analysis comparing national estimates of data from the BRFSS and the National Health Interview Survey (NHIS; which obtains information on medical conditions and health risk 
factors via within-household in-person interviews), it was shown that BRFSS estimates were similar to NHIS estimates for 13 of 14 measures examined, suggesting that any effect of telephone versus in-person interview on the quality of the information obtained was negligible (45). This burden of evidence then suggests that random digit dial telephone surveys can be an invaluable addition to the public health and epidemiologic armamentarium. In the context of assessments of large geographic areas such as the New York City metropolitan area, where the organization of representative in-person surveys would be logistically challenging and for most purposes prohibitively expensive, random digit dial surveys provide an efficient method of sampling of the general population.

One of the primary critiques of the use of telephone surveys frequently is that response rates in these assessments are lower than typical in-person epidemiologic assessments. Pinpointing an exact response rate in telephone surveys is often difficult due to the challenge in classifying indeterminate cases. Using standard definitions established by The American Association of Public Opinion Research (46), our study reports survey cooperation $(56 \%)$ and response rates $(34 \%)$ that are within the acceptable range for comparable random digit telephone surveys. The BRFSS response rates vary from year to year and from state to state, but the overall decrease in BRFSS response rates is well documented, with median response rates across states falling from a high of $71.4 \%$ in 1993 to a low of $48.9 \%$ in 2000 . Surveys conducted by "official organizations," such as health departments and the government typically have higher response rates than research surveys conducted by academic or non-profit institutions (47). Importantly, recent analyses of BRFSS data have shown that for a range of response rates for telephone surveys between $30 \%$ and $70 \%$, the response rates were at most weakly associated with bias (48). In one analysis, it was shown that although a larger difference in response rate was associated with larger differences in estimates of cigarette smoking prevalence between the BRFSS and the in-person Current Population Survey (CPS), the effects were small with a 45 percentage point difference in response rates having a predicted difference in smoking prevalence estimates of 1.5 percentage points. In analysis comparing data from two identical surveys with response rates of $61 \%$ and $36 \%$, very few significant differences were found across 91 comparisons (49). This developing research in the field suggests a weak association between response rates and epidemiologic estimates. Ultimately, further effort to recruit more reluctant non-participants may both be unethical and may itself introduce bias, since the reluctantly recruited participants potentially have reasons for providing false or misleading responses.

\section{REFERENCES}

1. Pole N, Best SR, Weiss DS, Metzler T, Liberman AM, Fagan J, et al. Effects of gender and ethnicity on duty-related post-traumatic stress symptoms among urban police officers. J Nerv Ment Dis. 2001;189:442-448.

2. Penk WE, Robinowitz R, Black J, Dolan M, Bell W, Dorsett D, et al. Ethnicity: Post-traumatic stress disorder (PTSD) differences among black, white, and Hispanic veterans who differ in degrees of exposure to combat in Vietnam. J Clin Psychol. 1989;45(5):729-735.

3. Kulka RA, Schlenger WE, Fairbank JA, Hough RL, Jordan BK, Marmar $\mathrm{CR}$, et al. Trauma and the Vietnam War generation: Report of findings form the National Vietnam Veterans Readjustment Study. New York: Brunner/Mazel; 1990.

4. Ortega AN, Rosenheck R. Post-traumatic stress disorder among Hispanic Vietnam veterans. Am J Psychiatry. 2000;157:615-619.

5. Ruef AM, Litz BT, Schlenger WE. Hispanic ethnicity and risk for combatrelated post-traumatic stress disorder. Hispanic ethnicity and risk for combat-related posttraumatic stress disorder. Cultur Divers Ethnic Minor Psychol. 2000;6(3):235-251.

6. Kessler RC, Sonnega A, Bromet E, Hughes M, Nelson CB. Post-traumatic stress disorder in the National Comorbidity Survey. Arch Gen Psychiatry. 1995;52(12):1048-1060.

7. Bromet E, Sonnega A, Kessler RC. Risk factors for DSM-III-R posttraumatic stress disorder: Findings from the National Comorbidity Survey. Am J Epidemiol. 1998;147:353-361.

8. Brewin CR, Andrews B, Valentine JD. Meta-analysis of risk factors for post-traumatic stress disorder in trauma-exposed adults. J Consult Clin Psychol. 2000;68(5):746-766.

9. Ozer EJ, Best SR, Lipsey TL, Weiss DS. Predictors of post-traumatic stress disorder: A meta-analysis. Psychol Bull. 2003;129(1):52-73.

10. Schlenger WE, Caddell JM, Ebert L, Jordan KB, Rourke KM, Wilson D, et al. Psychological reactions to terrorist attacks: Findings form the National Study of Americans' Reactions to September 11. JAMA. 2002;288:581588 .

11. Silver RC, Holman EA, McIntosh DN, Poulin M, Gil-Rivas V. Nationwide longitudinal study of psychological responses to September 11. JAMA. 2002;288:1235-1244

12. Galea S, Ahern J, Resnick H, Kilpatrick D, Bucuvalas M, Gold J, et al. Psychological sequelae of the September $11^{\text {th }}$ attacks in Manhattan, New York City. N Engl J Med. 2002;346:982-987.

13. Galea S, Vlahov D, Resnick H, Ahern J, Susser E, Gold J, et al. Trends in probable post-traumatic stress disorder in New York City after the September 11 terrorist attacks. Am J Epidemiol. 2003;158(6):514-524.

14. Dunn C, Deroo L, Rivara FP. The use of brief interventions adapted from motivational interviewing across behavioral domains: A systematic review. Addiction. 2001;96:1725-1742.

15. Acosta JK, Levenson RL Jr. Observations from Ground Zero at the World Trade Center in New York City, Part II: Theoretical and clinical considerations. Int J Emerg Ment Health. 2002;4(2):119-126.

16. Vlahov D, Galea S, Resnick H, Ahern J, Boscarino JA, Bucuvalas M, et al. Increased consumption of cigarettes, alcohol, and marijuana among Manhattan residents after the September $11^{\text {th }}$ terrorist attacks. Am J Epidemiol. 2002;555:988-996.

17. Freedy JR, Kilpatrick DG, Resnick HS. Natural disasters and mental health: Theory, assessment, and intervention. In: Allen R, ed. Handbook of Postdisaster Interventions. [special issue]. J Soc Behav Personal 1993;8(5):49_ 103.

18. American Psychiatric Association. Diagnostic and Statistical Manual of Mental Disorders. 4th ed. Washington, DC: American Psychiatric Association; 1995.

19. Spitzer RL, Williams JBW, Gibbon M, First MB. The structural clinical interview for DSM-III-R (SCID) I: History, rationale, and description. Arch Gen Psychiatry. 1992;49:624-629. 
20. Kilpatrick DG, Resnick HS, Freedy JR, Pelcovitz D, Resick PA, Roth S et al. The post-traumatic stress disorder field trial: Evaluation of the PTSD construct—criteria A through E. In: Widiger TA, Frances AJ, Pincus HA, First MB, Ross R, Davis W, eds. DSM-IV Sourcebook. v. 4. Washington, DC: American Psychiatric Association Press; 1998;803-844.

21. Kilpatrick DG, Acierno R, Resnick HS, Saunders BE, Best CL. A 2-year longitudinal analysis of the relationships between violent assault and substance use in women. J Consult Clin Psychol. 1997;65(5):834-847.

22. Hanson RF, Kilpatrick DG, Freedy R, Saunders BE. Los Angeles County after the 1992 civil disturbances: Degree of exposure and impact on mental health. J Consult Clin Psychol. 1995;63(6):987-996.

23. Resnick HS, Kilpatrick DG, Dansky BS, Saunders BE, Best C. Prevalence of civilian trauma and post-traumatic stress disorder in a representative national survey of women. J Consult Clin Psychol. 1993;61:984-991.

24. Breslau N, Kessler RC, Chilcoat HD, Schultz LR, Davis GC, Andreski P. Trauma and post-traumatic stress disorder in the community: The 1996 Detroit Area Survey of Trauma. Arch Gen Psychiatry. 1998;55(7):626-632.

25. Adler NE, Newman K. Socioeconomic disparities in health: Pathways and policies. Inequality in education, income, and occupation exacerbates the gaps between the health "haves" and "have-nots." Health Aff (Millwood). 2002;21(2):60-76.

26. Schulz AJ, Williams DR, Israel BA, Lempert LB. Racial and spatial relations as fundamental determinants of health in Detroit. Milbank Q. 2002;80(4): $677-707$.

27. Williams DR. Race, socioeconomic status, and health: The added effects of racism and discrimination. Ann N Y Acad Sci. 1999;896:173-188.

28. Escobar JI, Randolph ET, Puente G, Spiwak F, Asamen JK, Hill M, et al. Post-traumatic stress disorder in Hispanic Vietnam veterans. Clinical phenomenology and sociocultural characteristics. J Nerv Ment Dis. 1983; 171(10):585-596.

29. Harvey AG, Bryant RA. The relationship between Acute Stress Disorder and Post-traumatic Stress Disorder: A 2-year prospective evaluation. J Consult Clin Psychol. 1999;67(6):985-988.

30. Fullerton CS, Ursano RJ, Kao TC, Bharitya VR. Disaster-related bereavement: Acute symptoms and subsequent depression. Aviat Space Environ Med. 1999;70(9):902-909.

31. Lewis-Fernandez R, Guarnaccia PJ, Martinez IE, Salman E, Schmidt A, Liebowitz M. Comparative phenomenology of ataques de nervios, panic attacks, and panic disorder. Cult Med Psychiatry. 2002;26(2):199-223.

32. Lewis-Fernandez R, Garrido-Castillo P, Bennasar MC, Parrilla EM, Laria AJ, Ma G, Petkova E. Dissociation, childhood trauma, and ataque de nervios among Puerto Rican psychiatric outpatients. Am J Psychiatry. 2002;159(9):1603-1605.

33. Guarnaccia PJ, Rogler LH. Research on culture-bound syndromes: New directions. Am J Psychiatry. 1999;156(9):1322-1327.
34. Guarnaccia PJ, Rivera M, Franco F, Neighbors C. The experiences of ataques de nervios: Towards an anthropology of emotions in Puerto Rico. Cult Med Psychiatry. 1996;20(3):343-367.

35. Barlow D. Anxiety and its disorders. 2nd ed. New York, NY: Guilford Press; 2002

36. Weeks MF, Kulka RA, Lessler LT, Whitmore RW. Personal versus telephone surveys for collecting household health data at the local level. Am J Public Health. 1983;93(12):1389-1394.

37. Aneshensel CS, Frerichs RR, Clark V, Yokopenic PA. Telephone versus inperson surveys of community health status. Am J Public Health. 1982;72(9): 1017-1021.

38. Cannell CF, Groves RM, Miller PV. The effects of mode of data collection on health survey data. Proceedings of the Section on Survey Research Methods. Am Stat Assoc. 1980:115-118.

39. Simon GE, Revicki D, vonKorff M. Telephone assessment of depression severity. J Psychiatr Res. 1993;27(3):247-252.

40. Paulsen AS, Crowe RR, Noyes R, Pfohl B. Reliability of the telephone interview in diagnosing anxiety disorders. Arch Gen Psychiatry. 1988;45:62-63.

41. Dansky BS, Saladin ME, Brady KT, Kilpatrick DG, Resnick HS. Prevalence of victimization and post-traumatic stress disorder among women with substance use disorders: Comparison of telephone and in-person assessment samples. Int J Addict. 1995;30(9):1079-1099.

42. Merrill RM, Allen EW. Racial and ethnic disparities in satisfaction with doctors and health providers in the United States. Ethnicity Disease. 2003; 13(4):492-498,

43. Centers for Disease Control and Ethnicity \& Disease Prevention. Public health and aging: Health-related quality of life among low-income persons aged 45-64 years-United States, 1995-2001. Morb Mortal Wkly Rep. 2003;52(46):1120-1124

44. Karpati A, Lu X, Mostashari F, Thorpe L, Frieden TR. The health of North Queens. New York City Community Health Profiles. 2003;1(26):1-12.

45. Nelson DE, Powell-Griner E, Town M, Kovar MG. A comparison of national estimates from the National Health Interview Survey and the Behavioral Risk Factor Surveillance System. Am J Public Health. 2003;93(8):1335-1341.

46. The American Association for Public Opinion Research. Standard Definitions. Final Dispositions of Case Codes and Outcome Rates for Surveys. Available at: http://www.aapor.org/pdfs/newstandarddefinitions.pdf. Accessed 1 September 2003.

47. Mariolis P. Data accuracy: How good are our usual indicators? Proceedings of Statistics Canada Symposium 2001. Achieving Data Quality in a Statistical Agency: A Methodologic Perspective. Ottowa, Ontario: Statistics Canada; 2002.

48. Mariolis P. Response rates and data accuracy. American Association of Public Opinion Research, Oral presentation. Nashville, TN; May 2002.

49. Keeter S, Miller C, Kohut A, Groves RM, Presser S. Consequences of reducing nonresponse in a national telephone survey. Public Opinion Research Quarterly. 2000;64:125-148 